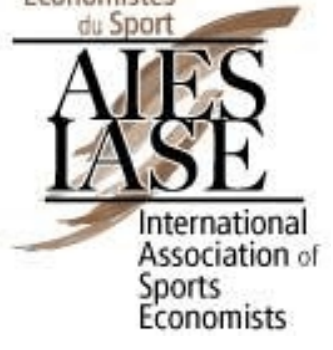

Working Paper Series, Paper No. 08-24

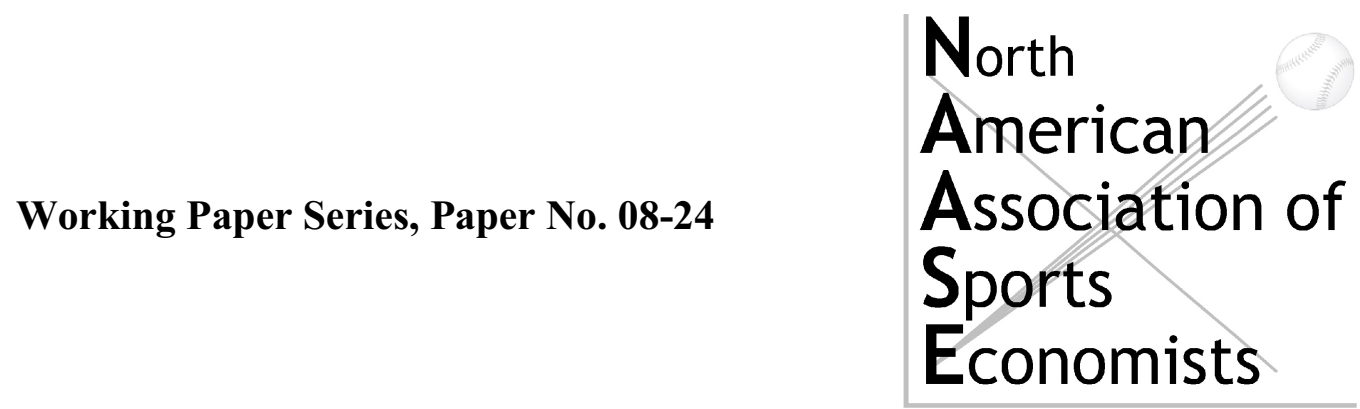

\title{
Corruption in Professional Sumo: An Update on Duggan and Levitt's Study
}

\author{
August 2008 \\ Updated June 2009
}

Helmut Dietl ${ }^{\dagger}$, Markus Lang ${ }^{\dagger \dagger}$, and Stephan Werner ${ }^{\dagger \dagger \dagger}$

\begin{abstract}
In the December 2002 issue of the American Economic Review, Mark Duggan and Steven D. Levitt published an article on corruption in professional sumo. In the present paper, we update Duggan and Levitt's study to take into account changes since January 2000 . We find strong statistical evidence that corruption is reduced after January 2000 but reappears in the period from 2003 to 2006. In addition, we can show that the non-linearity in the incentive structure disappears from 2000 to 2003 and reappears after 2003. These results confirm the findings of Duggan and Levitt, who suggest that the structure of promotion in rankings gives incentives to the sumo wrestlers to rig matches.
\end{abstract}

JEL Classification Codes: K42, L83, M52

Keywords: Sumo wrestling, corruption, incentive scheme, social ties, monitoring

We would like to thank Jörg Breitung, Jaume Garcia Villar, Leo Kahane, Michael Lama, Sarah Lein, two anonymous referees and the participants of the "11. Kollogium fuer

Personalwirtschaft" in Bonn for helpful comments and suggestions. We also gratefully acknowledge the financial support provided by the Swiss National Science Foundation (SNSF research projects no. 105270 and 120503) and the research fund of the University of Zurich.

'Institute for Strategy and Business Economics, University of Zurich, Plattenstrasse 14 CH-8032 Zurich, Switzerland, Phone: +41 (0) 4463453 11, Fax: +41 (0) 4463453 01, helmut.dietl@isu.uzh.ch

${ }^{\dagger}$ Institute for Strategy and Business Economics, University of Zurich, Plattenstrasse 14 CH-8032 Zurich, Switzerland, Phone: +41 (0) 4463453 11, Fax: +41 (0) 4463453 01, markus.lang@isu.uzh.ch

†'Institute for Strategy and Business Economics, University of Zurich, Plattenstrasse 14 CH-8032 Zurich, Switzerland, Phone: +41 (0) 4463453 11, Fax: +41 (0) 4463453 01, stephan.werner@isu.uzh.ch 


\section{Introduction}

In the December 2002 issue of the American Economic Review, Mark Duggan and Steven D. Levitt published an article entitled "Winning Isn't Everything: Corruption in Sumo Wrestling." In this article, the authors provide empirical evidence for match rigging in professional sumo, which has a more than 2,000-year-old history and is usually characterized by honesty, tradition and rituals. Despite sumo's long tradition and sometimes "ceremonial" character, the rules are comparatively simple and therefore provide the opportunity to analyze corruption on a microeconomic level. ${ }^{1}$

There are six tournaments each year. Each tournament lasts fifteen days with each wrestler fighting once per day. A fight is won whenever the opponent is pushed out of the ring or is the first to touch the ground with any part of his body other than the soles of his feet. The tournament is won by the wrestler who has the most wins. In the case of a tie for the most wins, the champion is determined by a playoff.

In sumo, all wrestlers are ranked. A wrestler's rank determines his social prestige as well as his monthly salary. The rank order is adjusted after each tournament. In general, wrestlers with more wins than losses move up while wrestlers with more losses than wins move down in the ranks. The total number of ranks that a wrestler moves up or down is determined by the number of wins and losses. Duggan and Levitt (D\&L) found out that with the exception of the eighth win, the correlation is linear: each win is worth approximately three ranks. The crucial eighth win, however, is worth eleven ranks, almost four times the value of an ordinary win. Consequently, a wrestler who achieves his eighth win usually gains more than his opponent loses.

Based on this incentive asymmetry, D\&L analyzed the results of all "critical" matches from January 1989 until January 2000 and found strong evidence for match rigging. They show that a wrestler who is on the margin for his eighth win is victorious with an abnormally high frequency while his opponent wins the next fight between the same wrestler-opponent pair with an abnormally high frequency.

In the present paper, we update D\&L's econometric research on corruption in sumo wrestling to the time after January $2000 .^{2}$ We find strong statistical evidence that corruption is reduced after January 2000 but reappears in the period from 2003 to 2006. In addition, we can show that the non-linearity in the incentive structure disappears from 2000 to 2003 and reappears after 2003. These results confirm the findings in D\&L, who suggest that the

\footnotetext{
${ }^{1}$ For a detailed description of the legal rules and social norms in Japanese sumo, see West (1997).

${ }^{2}$ Note that the data set of D\&L covers the periods from January 1989 until January 2000.
} 
structure of promotion in rankings gives incentives to sumo wrestlers to rig matches.

The use of econometrics to provide evidence of corruption in sports and other areas outside the classical domain of economics is growing rapidly. Jacob and Levitt (2003), for example, show that teachers inflate test scores of their students in school tests. Di Tella and Schargrodsky (2003) study the effect of audit intensity on prices of basic inputs during a crackdown on corruption in Buenos Aires. DellaVigna and La Ferrara (2006) use abnormal stock price movements of weapon-making companies to detect illegal arms trades. In sports, Taylor and Trogdon (2002) analyze the winning percentages of teams from the National Basketball Association (NBA), which are eliminated from the playoffs. They find that, in order to gain higher draft positions, these teams were 2.5 times more likely to lose than noneliminated teams. Wolfers (2006) provides statistical evidence for point shaving in NCAA basketball. Bernhardt and Heston (2008) present a method to distinguish between point shaving and "innocent" explanations of this asymmetry. Baldson, Fong, and Thayer (2007) show that regular-season champions in NCAA basketball often perform poorly in seasonending conference tournaments and suggest that corruption is a likely explanation for this systematic under-performance.

The remainder of this article is organized as follows. Section 2 describes the data and reports first evidence. In Section 3, we explain our econometric model and discuss further results. Section 4 concludes.

\section{Data and First Evidence}

We use three data sources to construct our data set. First, the webpage of scgroup.com provides (sometimes incomplete) statistics of all Japanese sumo tournaments since $1990 .^{3}$ The second and third sources of data are the homepages of the Japan Sumo Association and the Hungarian Sumo Association. ${ }^{4}$ Based on these three sources, we collect data for all tournaments from January 1995 until November 2006. After eliminating about 1.5\% of all matches due to inconsistencies and/or missing data, our data set consists of 33,734 matches involving 283 different wrestlers. For each match, we know the identity of the two wrestlers (including rank and stable), who wins, the month and year of the tournament, and the day of the match.

We divide our data into three periods to analyze the effect of D\&L's study on corruption in professional sumo before, during and after the period of the publication process. The first

\footnotetext{
${ }^{3}$ See http://www.scgroup.com/sumo.

${ }^{4}$ See http://www.sumo.or.jp and http://www.szumo.hu.
} 
period from January 1995 until January 2000 covers the period before D\&L presented their study. The second period covers the period of high public scrutiny from March 2000, when D\&L first presented their study, until May 2003. The third period consists of the remaining matches in our data set until November 2006. ${ }^{5}$ The breakpoint months that we have chosen are also consistent with allegations and media scrutiny of corruption in professional sumo. ${ }^{6}$

\section{Figure 1}

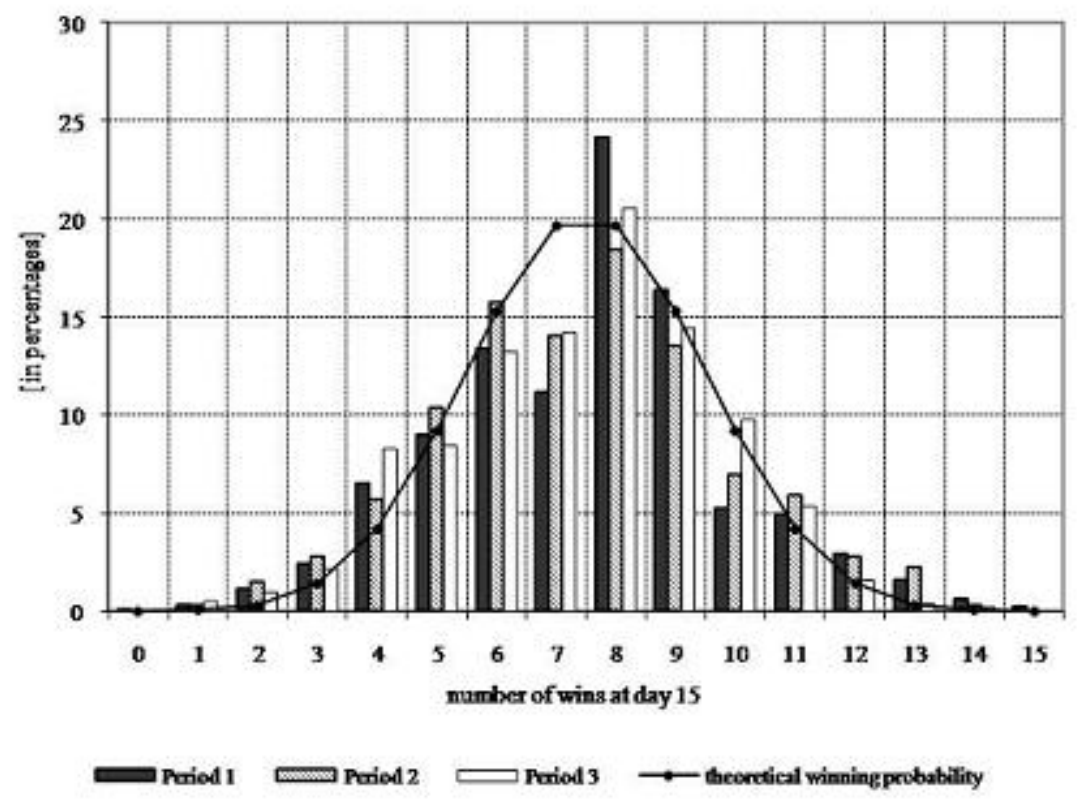

Figure 1 presents the preliminary evidence on how corruption has evolved before, during and after the publication process of the D\&L study. The figure reports the frequency of wins across wrestlers at the end of the tournament for the three periods and compares these frequencies with the theoretical distribution of wins that results from the assumption that each match is a coin toss. In period 1, i.e., before D\&L's study, wrestlers win exactly eight (seven) matches with an abnormally high (low) frequency. Only 12\% finish the tournaments with seven wins, but 24\% finish with exactly eight wins (in both cases, we expect frequencies of 19.6\%). In period 2, during the publication process, the frequency of finishing with (seven) eight wins (increases) decreases by (2.5\% points) $6 \%$ points, which implies that $14.5 \%$ wrestlers finish with seven wins and $18 \%$ finish with eight wins. In period 3, we observe again a similar pattern as in period 1 . That is, $14 \%$ of the wrestlers finish the tournaments with seven wins, and 20.5\% finish with exactly eight wins. A simple binomial test shows that

\footnotetext{
${ }^{5}$ We dropped all tournaments after the last tournament in November 2006 because another wave of allegations started in January 2007.

${ }^{6}$ We therefore have reviewed allegations in Sumo wrestling in the "International Herald Tribune Online" and in the "Japan Times Online" (with keywords "sumo allegations"). All our results are also robust with respect to changes in this periodization for up to three tournaments.
} 
the frequencies for seven and eight wins differ significantly from the theoretical frequencies in all three periods except for eight wins in period 2.

D\&L identified a sharp non-linearity in the incentive structure as the main reason for corruption. In Figure 2, we show how this incentive structure has evolved in the different periods. The figure depicts on the horizontal axis the number of wins a wrestler achieves in a certain tournament, and the vertical axis gives the resulting average rank change after this tournament. With the exception of the eighth win, each win is worth about three spots in the ranking in all three periods.

Figure 2

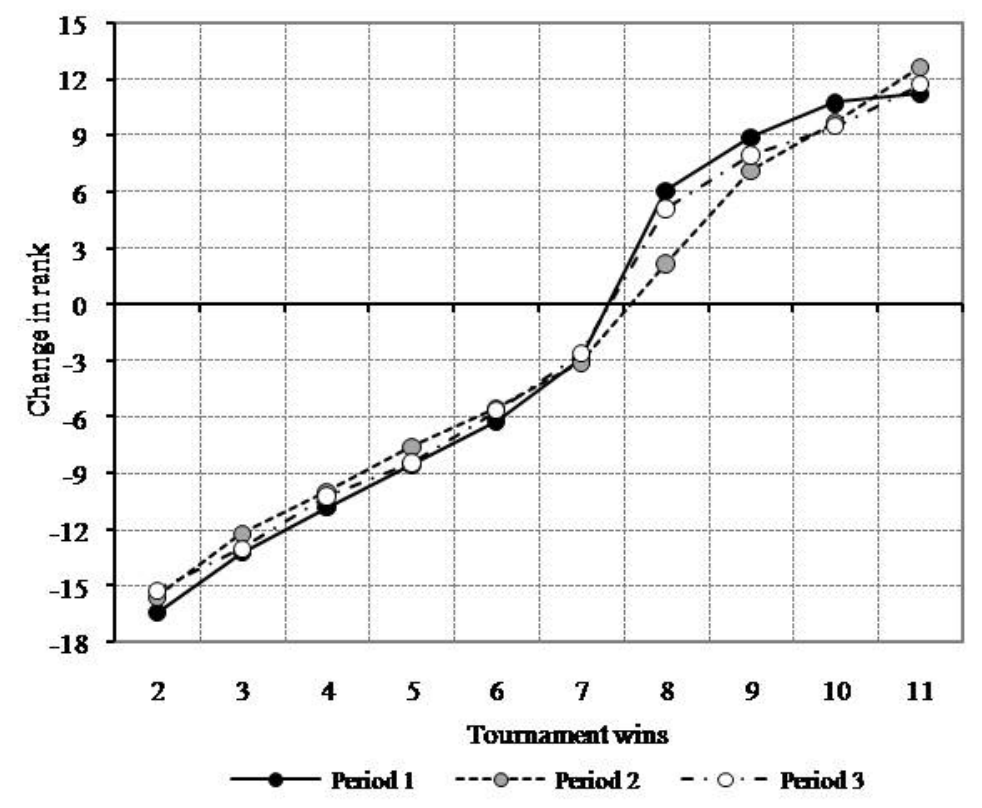

However, before D\&L's study in period 1, the eighth win was worth about eight spots in the rankings, almost three times the value of a typical victory. Consequently, a wrestler who entered the final match with seven wins would gain more than a wrestler with eight wins would lose. This non-linearity disappears after D\&L's study in period 2 because the value of the eighth win was decreased to four ranks, only slightly more than the value of an ordinary victory. This structural break can be interpreted as a response by the Japan Sumo Association, which produces the rankings, to the econometric study of D\&L. In period 3, however, the non-linearity in the incentive structure returns. The pattern in the incentive structure suggests that corruption decreases in period 2 and increases again in period 3. 


\section{Empirical Analysis and Further Evidence}

In order to confirm the claim that corruption in professional sumo wrestling has decreased in period 2 and has increased again in period 3, we estimate the following linear probability model:

$$
\begin{aligned}
\text { Win }_{i j t d}=\alpha+\beta \text { Bubble }_{i j t d} & +\gamma \text { Bubble }_{i j t d} \times \text { Timedummy }_{2} \\
& + \text { B Bubble }_{i j t d} \times \text { Timedummy }_{3} \\
& +\lambda \text { Rankdifference }_{i j t d}+\varepsilon_{i j t d}
\end{aligned}
$$

As in D\&L, the dependent variable Win in the regression model is a variable indicating whether wrestler $i$ wins the match against wrestler $j$ at day $d$ in tournament $t$. The unit of observation is a wrestler-opponent match. Bubble is a vector of dummy variables indicating whether a wrestler is on the margin for reaching eight wins or not: Day 15 takes the value 1 (1) if the wrestler (his opponent) has seven wins at the beginning of day 15. If neither of the wrestlers or both have seven wins, the dummy takes the value 0 . Day 14 takes the value $1(-1)$ if the wrestler (his opponent) has either seven or six wins at the beginning of day 14 and 0 otherwise. Day 13, Day 12 and Day 11 are constructed accordingly.

In contrast to D\&L, we introduce three time dummies. The variable Timedummy 2 is 1 for all matches in the second period, i.e., tournaments from March 2000 to May 2003, and 0 otherwise. Accordingly, the variable Timedummy $y_{3}$ is 1 for all matches in the third period until November 2006. Rankdifference is the difference between the ranks of the two opponents.

We estimate the linear probability model with fixed and random effects and account for heterogeneity by conditioning on the same wrestler-opponent pair when calculating the winning probabilities. Standard errors are corrected to account for the fact that there are two observations for each bout (one for each wrestler). Table 1 illustrates our estimations for the three-period model for the last five days of a tournament.

In period 1 , the excess winning probabilities are highly significant and take on values from around $8 \%$ for day 12 up to $20 \%$ for day 15 . We cannot identify any anomalies for day 11. In period 2, the reduction of the critical winning probabilities is highly significant for days 13, 14 and 15. Moreover, the probability of winning a critical match is only about $4 \%$ higher than expected on day 15 and approximately as high as theoretically expected on days 14 and $13 .^{7}$ In period 3 , the excess winning probability for all critical matches on day 15 is with $20 \%$ again as high as in the first period. For days 14 and 13, we observe only a weakly significant reduction of critical winning probabilities compared to period 1 . This reduction, however, is

\footnotetext{
${ }^{7}$ Note that for the models with no wrestler-opponent fixed effects, i.e., models (1) and (3), the excess winning probability on day 14 is about $3 \%$.
} 
Table 1

\begin{tabular}{|c|c|c|c|c|c|c|c|c|c|}
\hline & On the margin on: & (1) & & $(2)$ & & (3) & & (4) & \\
\hline \multirow[t]{6}{*}{ Period 1} & Day 15 & $\begin{array}{c}0.198 \\
(0.023)\end{array}$ & $* * *$ & $\begin{array}{c}0.185 \\
(0.026)\end{array}$ & $* * *$ & $\begin{array}{c}0.198 \\
(0.023)\end{array}$ & $* * *$ & $\begin{array}{c}0.184 \\
(0.026)\end{array}$ & $* * *$ \\
\hline & Day 14 & $\begin{array}{c}0.175 \\
(0.023)\end{array}$ & $* * *$ & $\begin{array}{c}0.155 \\
(0.026)\end{array}$ & $* * *$ & $\begin{array}{c}0.175 \\
(0.023)\end{array}$ & $* * *$ & $\begin{array}{c}0.152 \\
(0.026)\end{array}$ & $* * *$ \\
\hline & Day13 & $\begin{array}{c}0.133 \\
(0.026)\end{array}$ & $* * *$ & $\begin{array}{c}0.13 \\
(0.03)\end{array}$ & $* * *$ & $\begin{array}{c}0.132 \\
(0.026)\end{array}$ & $* * *$ & $\begin{array}{c}0.129 \\
(0.030)\end{array}$ & $* * *$ \\
\hline & Day 12 & $\begin{array}{c}0.083 \\
(0.029)\end{array}$ & $* * *$ & $\begin{array}{c}0.087 \\
(0.032)\end{array}$ & $* * *$ & $\begin{array}{c}0.082 \\
(0.029)\end{array}$ & $* * *$ & $\begin{array}{c}0.086 \\
(0.032)\end{array}$ & $* * *$ \\
\hline & Day 11 & $\begin{array}{c}0.003 \\
(0.034)\end{array}$ & & $\begin{array}{c}-0.001 \\
(0.038)\end{array}$ & & $\begin{array}{c}0.001 \\
(0.034)\end{array}$ & & $\begin{array}{l}-0.002 \\
(0.038)\end{array}$ & \\
\hline & Rankdifference & $\begin{array}{c}-0.002 \\
(0.001)\end{array}$ & $* * *$ & $\begin{array}{l}-0.001 \\
(0.001)\end{array}$ & * & $\begin{array}{c}-0.002 \\
(0.001)\end{array}$ & $* * *$ & $\begin{array}{c}-0.001 \\
(0.001)\end{array}$ & * \\
\hline \multirow[t]{6}{*}{ Period 2} & Day 15 & $\begin{array}{l}-0.162 \\
(0.062)\end{array}$ & $* * *$ & $\begin{array}{l}-0.136 \\
(0.071)\end{array}$ & $*$ & $\begin{array}{l}-0.165 \\
(0.062)\end{array}$ & $* * *$ & $\begin{array}{c}-0.14 \\
(0.071)\end{array}$ & $* *$ \\
\hline & Day 14 & $\begin{array}{c}-0.145 \\
(0.045)\end{array}$ & $* * *$ & $\begin{array}{c}-0.144 \\
(0.048)\end{array}$ & $* * *$ & $\begin{array}{l}-0.143 \\
(0.045)\end{array}$ & $* * *$ & $\begin{array}{l}-0.141 \\
(0.048)\end{array}$ & $* * *$ \\
\hline & Day13 & $\begin{array}{l}-0.124 \\
(0.049)\end{array}$ & $* *$ & $\begin{array}{l}-0.135 \\
(0.056)\end{array}$ & $* *$ & $\begin{array}{l}-0.126 \\
(0.048)\end{array}$ & $* * *$ & $\begin{array}{l}-0.138 \\
(0.056)\end{array}$ & $* *$ \\
\hline & Day 12 & $\begin{array}{c}-0.074 \\
(0.050)\end{array}$ & & $\begin{array}{l}-0.081 \\
(0.059)\end{array}$ & & $\begin{array}{c}-0.072 \\
(0.050)\end{array}$ & & $\begin{array}{l}-0.081 \\
(0.059)\end{array}$ & \\
\hline & Day 11 & $\begin{array}{c}0.035 \\
(0.061)\end{array}$ & & $\begin{array}{c}0.056 \\
(0.070)\end{array}$ & & $\begin{array}{c}0.043 \\
(0.061)\end{array}$ & & $\begin{array}{c}0.061 \\
(0.070)\end{array}$ & \\
\hline & Rankdifference & $\begin{array}{l}-0.003 \\
(0.001)\end{array}$ & $* * *$ & $\begin{array}{l}-0.003 \\
(0.001)\end{array}$ & $* * *$ & $\begin{array}{l}-0.003 \\
(0.001)\end{array}$ & $* * *$ & $\begin{array}{c}-0.003 \\
(0.001)\end{array}$ & $* * *$ \\
\hline \multirow[t]{9}{*}{ Period 3} & Day 15 & $\begin{array}{l}-0.074 \\
(0.049)\end{array}$ & & $\begin{array}{l}-0.001 \\
(0.054)\end{array}$ & & $\begin{array}{l}-0.074 \\
(0.049)\end{array}$ & & $\begin{array}{c}0.002 \\
(0.054)\end{array}$ & \\
\hline & Day 14 & $\begin{array}{l}-0.110 \\
(0.038)\end{array}$ & $* * *$ & $\begin{array}{l}-0.108 \\
(0.045)\end{array}$ & $* *$ & $\begin{array}{l}-0.111 \\
(0.038)\end{array}$ & $* * *$ & $\begin{array}{l}-0.107 \\
(0.045)\end{array}$ & $* *$ \\
\hline & Day13 & $\begin{array}{c}-0.101 \\
(0.040)\end{array}$ & $* *$ & $\begin{array}{c}-0.102 \\
(0.046)\end{array}$ & $* *$ & $\begin{array}{l}-0.100 \\
(0.040)\end{array}$ & $* *$ & $\begin{array}{c}-0.101 \\
(0.046)\end{array}$ & $* *$ \\
\hline & Day 12 & $\begin{array}{c}-0.08 \\
(0.044)\end{array}$ & & $\begin{array}{l}-0.068 \\
(0.051)\end{array}$ & & $\begin{array}{l}-0.079 \\
(0.044)\end{array}$ & $*$ & $\begin{array}{c}-0.065 \\
(0.051)\end{array}$ & \\
\hline & Day 11 & $\begin{array}{c}0.053 \\
(0.052)\end{array}$ & & $\begin{array}{c}0.071 \\
(0.059)\end{array}$ & & $\begin{array}{c}0.054 \\
(0.052)\end{array}$ & & $\begin{array}{c}0.073 \\
(0.059)\end{array}$ & \\
\hline & Rankdifference & $\begin{array}{l}-0.005 \\
(0.001)\end{array}$ & $* * *$ & $\begin{array}{l}-0.005 \\
(0.001)\end{array}$ & $* * *$ & $\begin{array}{l}-0.005 \\
(0.001)\end{array}$ & $* * *$ & $\begin{array}{l}-0.005 \\
(0.001)\end{array}$ & $* * *$ \\
\hline & Constant & $\begin{array}{c}0.502 \\
(0.003)\end{array}$ & $* * *$ & $\begin{array}{c}0.502 \\
(0.000)\end{array}$ & $* * *$ & $\begin{array}{c}0.509 \\
(0.033)\end{array}$ & $* * *$ & $\begin{array}{c}0.504 \\
(0.038)\end{array}$ & $* * *$ \\
\hline & $\begin{array}{l}\text { Wrestler and opponent } \\
\text { fixed effects }\end{array}$ & No & & Yes & & No & & Yes & \\
\hline & Time fixed effects & No & & No & & Yes & & Yes & \\
\hline
\end{tabular}

Notes: The dependent variable in all regression models is an indicator variable corresponding to whether or not a wrestler wins the bout. Values reported in the table are coefficients combined with an indicator variable taking the value 1 if only the wrestler is on the margin for achieving eight wins, -1 if only the opponent is on the margin for achieving eight wins, and 0 otherwise. Standard errors (in parenthesis) are corrected to account for the fact that there are two observations per bout (one for each wrestler).

*** significant at the $1 \%$ level. ** significant at the $5 \%$ level. * significant at the $10 \%$ level. 
smaller than in period $2 .^{8}$

The results of our three-period model show that the abnormalities in the winning probabilities disappear in period 2 when wrestlers face a linear incentive structure. The abnormalities reappear in period 3 when the wrestlers again face a non-linear incentive structure. This confirms the findings of D\&L, who suggest that the structure of promotion in rankings gives incentives to the sumo wrestlers to rig matches.

In order to further investigate the source of these abnormalities in winning probabilities, we follow D\&L and analyze the time structure of match rigging by considering the subsequent three matches of the same wrestler-opponent pair after a bubble match. If corruption is the reason that wrestlers on the bubble have an abnormally high winning probability, then the opponent must be compensated for losing the match. This compensation can be made in cash or in promises to return the favor by throwing a match in the future.

We aggregate the variables Day 15, Day 14, and Day 13 into one variable Bubble. This dummy variable takes the value 1 if one of the two opponents is on the path for his eighth win on days 13, 14 or 15 and 0 otherwise. Again, we use Rankdifference as the control variable. The results are presented in Table 2 .

Table 2

\begin{tabular}{|c|c|c|c|c|c|c|c|c|c|c|c|c|}
\hline \multirow[t]{2}{*}{ Variable } & \multicolumn{4}{|c|}{ Period 1} & \multicolumn{3}{|c|}{ Period 2} & \multicolumn{5}{|c|}{ Period 3} \\
\hline & (1) & & (2) & & (1) & & $(2)$ & & (1) & & (2) & \\
\hline Bubble Match & $\begin{array}{c}0.134 \\
(0.021)\end{array}$ & $* * *$ & $\begin{array}{c}0.132 \\
(0.028)\end{array}$ & $* * *$ & $\begin{array}{l}-0.127 \\
(0.037)\end{array}$ & $* * *$ & $\begin{array}{l}-0.126 \\
(0.041)\end{array}$ & $* * *$ & $\begin{array}{l}-0.044 \\
(0.023)\end{array}$ & $* *$ & $\begin{array}{l}-0.049 \\
(0.024)\end{array}$ & $* *$ \\
\hline $\begin{array}{l}\text { First Match after } \\
\text { the Bubble }\end{array}$ & $\begin{array}{l}-0.097 \\
(0.028)\end{array}$ & $* * *$ & $\begin{array}{l}-0.095 \\
(0.031)\end{array}$ & $* * *$ & $\begin{array}{c}0.087 \\
(0.041)\end{array}$ & $* * *$ & $\begin{array}{c}0.094 \\
(0.044)\end{array}$ & $* * *$ & $\begin{array}{l}-0.039 \\
(0.022)\end{array}$ & $*$ & $\begin{array}{l}-0.042 \\
(0.025)\end{array}$ & $*$ \\
\hline $\begin{array}{l}\text { Second Match after } \\
\text { the Bubble }\end{array}$ & $\begin{array}{l}-0.055 \\
(0.039)\end{array}$ & & $\begin{array}{l}-0.053 \\
(0.043)\end{array}$ & & $\begin{array}{l}-0.037 \\
(0.041)\end{array}$ & & $\begin{array}{l}-0.029 \\
(0.046)\end{array}$ & & $\begin{array}{c}0.036 \\
(0.045)\end{array}$ & & $\begin{array}{c}0.035 \\
(0.047)\end{array}$ & \\
\hline $\begin{array}{l}\text { Third Match after } \\
\text { the Bubble }\end{array}$ & $\begin{array}{l}-0.009 \\
(0.069)\end{array}$ & & $\begin{array}{l}-0.008 \\
(0.073)\end{array}$ & & $\begin{array}{c}0.005 \\
(0.046)\end{array}$ & & $\begin{array}{c}0.003 \\
(0.049)\end{array}$ & & $\begin{array}{c}0.001 \\
(0.053)\end{array}$ & & $\begin{array}{c}0.001 \\
(0.061)\end{array}$ & \\
\hline $\begin{array}{l}\text { Wrestler and } \\
\text { opponent fixed effects }\end{array}$ & No & & Yes & & No & & Yes & & No & & Yes & \\
\hline
\end{tabular}

Notes: The dependent variable in all regression models is an indicator variable corresponding to whether or not a wrestler wins the bout. Standard errors (in parenthesis) are corrected to account for the fact that there are two observations per bout (one for each wrestler). The constant is $0.499(0.035)$ in the model with no wrestleropponent fixed effects and 0.502 (0.036) in the model with wrestler-opponent fixed effects. Both models include time fixed effects. The number of observations is equal to 33.374 and $\mathrm{R}^{2}$ is 0.012 and 0.015 , respectively. *** significant at the $1 \%$ level. ** significant at the $5 \%$ level. * significant at the $10 \%$ level.

\footnotetext{
${ }^{8}$ By considering only two periods, where the first period covers the period before D\&L presented their study (i.e., January 1995-January 2000) and the second period runs from March 2000 until November 2006, we derive the following results: As in the three-period model, the excess winning probabilities are highly significant for days 12-15 in period 1. For period 2, however, only the winning probabilities for days 13 and 14 show a weakly significant decrease compared with their abnormally high values from period 1 .
} 
In period 1, wrestlers win their bubble match with a probability that is about $13 \%$ higher than expected, which is consistent with our previous findings. In the next meeting of the same opponents, the wrestler who was on the margin in the last meeting is about $10 \%$ less likely to win than expected. Both values are highly significant. The coefficients for the second and third meeting after the bubble match are not significant. In period 2, both the excess winning probability in the bubble match and the excess losing probability in the next match against the same opponent disappear. In period 3, however, the excess winning probability in the bubble match is approximately $9 \%$, nearly as abnormally high as in period 1 . The excess losing probability in the subsequent meeting between both wrestlers is with approximately $13 \%$ even lower than in period 1.

This pattern suggests that a part of the compensation to throw a match is the promise of the opponent to return the favor in the next meeting. This finding provides further evidence that corruption and not motivation is the source of the excess winning probabilities in periods 2 and 3.

In order to further strengthen our claim, we run another regression and add the following new variables to our model: Same Group, Sudden Weakness, Special Prize and Year before Retirement. Again, we use Rankdifference as the control variable. Table 3 shows the results.

The first variable, Same Group, is a dummy variable that takes the value 1 if both wrestlers belong to stables from the same group and 0 otherwise. By adding the dummy variable Same Group, we want to test whether corruption is more likely between wrestlers from the same stable group than between wrestlers from different stable groups.

In sumo, each wrestler is affiliated with a sumo stable (Heya) where he lives and practices. This affiliation usually lasts for the wrestler's entire active career. Each stable is run by a stable master, a former wrestler who was granted the right to open his own stable. There are strong social ties between the stables of a group because an active wrestler has to ask permission from the master of his stable to open a new stable after retiring from his active career. ${ }^{9}$ In addition, a wrestler must purchase one of the limited licenses, which cost more than 200 million Yen (US\$1.9 million), and get permission from the Japan Sumo Association. There are currently 53 stables. With one exception, each stable belongs to one of five stable groups. While wrestlers from the same stable are usually not matched against each other within a tournament, there are many matches between wrestlers from different stables within the same group.

\footnotetext{
${ }^{9}$ Only a yokozuna (grand champion) may directly ask the Japan Sumo Association for the right to open his own stable.
} 
Table 3

\begin{tabular}{|c|c|c|c|c|c|c|c|c|c|c|c|c|}
\hline \multirow[t]{2}{*}{ Variable } & \multicolumn{4}{|c|}{ Period 1} & \multicolumn{4}{|c|}{ Period 2} & \multicolumn{4}{|c|}{ Period 3} \\
\hline & (1) & & (2) & & (1) & & (2) & & (1) & & (2) & \\
\hline Bubble Match & $\begin{array}{c}0.093 \\
(0.017)\end{array}$ & $* * *$ & $\begin{array}{c}0.091 \\
(0.017)\end{array}$ & $* * *$ & $\begin{array}{c}-0.118 \\
(0.032)\end{array}$ & $* * *$ & $\begin{array}{l}-0.105 \\
(0.032)\end{array}$ & $* * *$ & $\begin{array}{l}-0.043 \\
(0.021)\end{array}$ & $* *$ & $\begin{array}{l}-0.049 \\
(0.024)\end{array}$ & $* *$ \\
\hline Same Group & $\begin{array}{c}0.090 \\
(0.031)\end{array}$ & $* * *$ & $\begin{array}{c}0.087 \\
(0.032)\end{array}$ & $* * *$ & $\begin{array}{l}-0.116 \\
(0.053)\end{array}$ & $* *$ & $\begin{array}{l}-0.120 \\
(0.054)\end{array}$ & $* *$ & $\begin{array}{l}-0.095 \\
(0.037)\end{array}$ & $* * *$ & $\begin{array}{l}-0.093 \\
(0.035)\end{array}$ & $* * *$ \\
\hline Sudden Weakness & $\begin{array}{c}0.102 \\
(0.028)\end{array}$ & $* * *$ & $\begin{array}{c}0.110 \\
(0.030)\end{array}$ & $* * *$ & $\begin{array}{l}-0.098 \\
(0.057)\end{array}$ & $*$ & $\begin{array}{l}-0.097 \\
(0.058)\end{array}$ & * & $\begin{array}{c}-0.032 \\
(0.041)\end{array}$ & & $\begin{array}{l}-0.031 \\
(0.045)\end{array}$ & \\
\hline Special Price & $\begin{array}{c}0.028 \\
(0.128)\end{array}$ & & $\begin{array}{c}0.026 \\
(0.132)\end{array}$ & & $\begin{array}{c}0.016 \\
(0.233)\end{array}$ & & $\begin{array}{c}0.014 \\
(0.242)\end{array}$ & & $\begin{array}{c}0.011 \\
(0.196)\end{array}$ & & $\begin{array}{c}0.013 \\
(0.209)\end{array}$ & \\
\hline Year before Retirement & $\begin{array}{c}0.052 \\
(0.056)\end{array}$ & & $\begin{array}{c}0.052 \\
(0.059)\end{array}$ & & $\begin{array}{c}-0.023 \\
(0.143)\end{array}$ & & $\begin{array}{l}-0.021 \\
(0.150)\end{array}$ & & $\begin{array}{c}0.041 \\
(0.087)\end{array}$ & & $\begin{array}{c}0.039 \\
(0.091)\end{array}$ & \\
\hline Rankdifference & $\begin{array}{l}-0.005 \\
(0.001)\end{array}$ & $* * *$ & $\begin{array}{c}-0.005 \\
(0.001)\end{array}$ & $* * *$ & $\begin{array}{c}-0.002 \\
(0.001)\end{array}$ & $*$ & $\begin{array}{c}-0.002 \\
(0.001)\end{array}$ & $*$ & $\begin{array}{l}-0.003 \\
(0.001)\end{array}$ & $* * *$ & $\begin{array}{l}-0.003 \\
(0.001)\end{array}$ & $* * *$ \\
\hline $\begin{array}{l}\text { Wrestler and opponent } \\
\text { fixed effects }\end{array}$ & No & & Yes & & No & & Yes & & No & & Yes & \\
\hline
\end{tabular}

Notes: The dependent variable in all regression models is an indicator variable corresponding to whether or not a wrestler wins the bout. The table reports the coefficients on the interaction terms between the various factors and the outcome of the bubble match and reflects the impact that a variable has on winning percentages when a wrestler is on the bubble, above and beyond any impact that the variable has in nonbubble tournaments. The main effects are also included in the regression but are not reported in the tables. Standard errors (in parenthesis) are corrected to account for the fact that there are two observations per bout (one for each wrestler). The constant is $0.498(0.019)$ in the model with no wrestler-opponent fixed effects and 0.500 (0.040) in the model with wrestler-opponent fixed effects. Both models include time fixed effects. Number of observations is equal to 33.374 and $\mathrm{R}^{2}$ is 0.019 and 0.020 , respectively.

*** significant at the $1 \%$ level. ** significant at the $5 \%$ level. * significant at the $10 \%$ level

The second variable, Sudden Weakness, is a dummy variable that takes the value 1 if the opponent is a "suspicious" wrestler and 0 otherwise. ${ }^{10}$ We define a wrestler as "suspicious" if he starts a tournament extremely well twice and then suddenly loses a series of matches towards the end of the tournament. In other words, he is "suspicious" if he has the following win-loss pattern in two or more tournaments: he has either seven, eight or nine wins on day 9 or seven or eight wins on day 8 and eight, nine, ten or eleven wins on day 15. The variable sudden weakness is constructed such that it excludes the tournament in question. For example, if a wrestler shows sudden weakness in only his 7th tourney, the Sudden Weakness variable is equal to 1 in all tourneys for that wrestler except the 7 th tourney. ${ }^{11}$ In our data, we identify 223 cases involving 101 wrestlers with the mentioned win-loss pattern in at least one tournament. Of those, 59 wrestlers show this win-loss pattern for at least two tournaments. Interestingly, all wrestlers who have been publicly accused by insiders of being corrupt

\footnotetext{
${ }^{10}$ Note that D\&L analyze the outcome of bubble matches between 29 wrestlers who are alleged to be "corrupt" and 14 wrestlers who are claimed to be "clean".

${ }^{11}$ We are grateful to an anonymous referee who suggested excluding the tournament in question.
} 
belong to this group of 59 "suspicious" wrestlers. ${ }^{12}$

Finally, as in D\&L, we further analyze motivational effects by including the variables Special Prize and Year before Retirement. The Japan Sumo Association can award up to three special prizes for exceptional performance during a tournament: Outstanding Performance Prize (Shukun-sho), Technique Prize (Gino-sho) and Fighting Spirit Prize (Kanto-sho). It is a de facto standard that a newcomer to the top division who manages a 10-5 record or better in his first tournament will be awarded one of the three prizes. We expect that a wrestler who has the chance to win one of these prestigious prizes is more motivated to win against an opponent on the Bubble than wrestlers who are not in the race for a special prize. Therefore, we include the dummy variable Special Prize, which takes the value 1 if the wrestler faces an opponent in his bubble match who is in the race for a special prize, and 0 otherwise. On the other hand, opponents who are close to retirement are probably less motivated. We control for this effect by including the variable Year before retirement, which is 1 if the wrestler on the bubble faces an opponent who is within one year from retirement, and 0 otherwise. ${ }^{13}$

For period 1, we estimate an excess winning probability of approximately $9 \%$ on the Bubble. This excess winning probability disappears in period 2. For period 3, we observe again an excess winning probability of about $5 \%$ on the bubble, albeit at significantly lower values than in period 1.

Moreover, similar to D\&L, we derive that motivational effects seem to have no impact on the behavior of sumo wrestlers because neither the variable Special Prize nor the variable Year before Retirement is statistically significant.

We identify, however, highly significant effects of the variable Same Group. In period 1, wrestlers on the Bubble have a 9\% higher winning probability against opponents from their stable group than against opponents from other stable groups. ${ }^{14}$ This result suggests that match rigging in professional sumo is not primarily the result of bilateral corruption among wrestlers but seems to be a well-organized phenomenon that is planned and controlled by social ties within the sumo network. This "same group” effect, however, disappears in periods 2 and 3. This finding suggests that, after the publication of the D\&L study, reciprocity agreements between stable groups may have been replaced by other mechanisms.

In order to further analyze the behavior of suspicious wrestlers, we consider the variable Sudden Weakness. In period 1, facing a "suspicious" rather than a "regular" opponent

\footnotetext{
${ }^{12}$ See Shukan Gendai: http://www.bitway.ne.jp

${ }^{13}$ Note that we eliminate wrestlers who are retired due to injuries.

${ }^{14}$ These results confirm the finding in D\&L who suggest that reciprocity agreements between stables appear to exist, leading to stable-coordinated collusion. D\&L, however, do not consider different stable groups.
} 
increases the winning probability of wrestlers who are on the bubble by around $10 \%$. This effect disappears in period 2 and reappears in period 3. The main reason for this structural change in behavior can be found in the linearization of the incentive structure. Before D\&L's study, i.e., in period 1, "sudden weakness" was an attractive strategy because the marginal benefits of the ninth, tenth and eleventh wins were very small compared to the marginal benefit of the eighth win. After the linearization of the incentive structure in period 2, it became unattractive to lose a series of matches towards the end of the tournament after a strong performance in the first half of the tournament. However, this strategy became attractive again in period 3.

\section{Conclusion}

The study by Duggan and Levitt (2002) provides empirical evidence for corruption in professional sumo. In our paper, we update D\&L's study to the time after January 2000, and we analyze how corruption in sumo wrestling has evolved by comparing the outcome of "critical" matches before, during and after the period of the publication process.

Our analysis shows that the percentage of wrestlers who finish the tournament with exactly eight wins is significantly lower after January 2000 than its abnormally high value before that date. Moreover, wrestlers who are on the margin for their eighth victory win their critical matches with a significantly lower frequency than before 2000. However, after the period of the publication process, i.e., from 2003 to 2006, the abnormally high winning probabilities in bubble matches reappear.

D\&L suggest that the structure of promotion in rankings gives incentives to the sumo wrestlers to rig matches. Until 2000, the crucial eighth win was approximately three times as valuable as an ordinary win. Consequently, a wrestler with seven wins had much more at stake than a wrestler who is not on the margin for his eighth win. In our paper, we have shown that the non-linearity in the incentive structure disappears from 2000 to 2003 and reappears after 2003. The temporary linearization of the incentive scheme and payoff structure can be interpreted as a reaction of the Japanese Sumo Association in order to eliminate the economic basis of match rigging.

Moreover, we confirm the finding in D\&L that wrestlers who win their bubble matches before 2000 with an abnormally high probability will lose the next match against the same opponent with an abnormally high probability. In addition, we show that this pattern disappears in the period from 2000 to 2003 but reappears again after 2003. Finally, we identify two additional strategies for match rigging: sudden weakness and stable-group 
reciprocity.

Econometrics has reached a stage that enables researchers to conduct "forensic" studies at relatively low costs. Researchers do not need full and complete information to detect corruption. With modern econometric methods, researchers can find anomalies and identify their causes. From this perspective, forensic econometrics is an effective and efficient means to fight corruption. Therefore, we strongly encourage future research in this area.

\section{References}

Balsdon, E., Fong, L. \& Thayer, M. (2007). Corruption in College Basketball? Evidence of Tanking in Postseason Conference Tournaments. Journal of Sports Economics, 8, 1938.

Beck, N. \& Katz, J. N. (1995). What to do (and not to do) with Time-Series Cross-Section Data. The American Political Science Review, 89, 634-657.

Bernhardt, D. \& Heston, S. L. (2008). Point Shaving in College Basketball: A Cautionary Tale for Forensic Economics. Forthcoming in Economic Inquiry.

DellaVigna, S. \& La Ferrara, E. (2007). Detecting Illegal Arms Trade. NBER Working Paper No. 13355. Available at SSRN: http://www.nber.org/papers/w13355

Di Tella, R. \& Schargrodsky, E. (2003). The Role of Wages and Auditing during a Crackdown on Corruption in the City of Buenos Aires. Journal of Law \& Economics, 46, 269-92.

Duggan, M. \& Levitt, S. (2002). Winning Isn’t Everything: Corruption in Sumo Wrestling. American Economic Review, 92, 1594-1605

Jacob, B. A. \& Levitt, S. D. (2003). Rotten Apples: An Investigation of the prevalence and predictors of teacher cheating. Quarterly Journal of Economics, 118, 843-77

Taylor, B. A. \& Trogdon, J. G. (2002). Losing to win: Tournament incentives in the National Basketball Association. Journal of Labor Economics, 20, 23-41

West, M. D. (1997). Legal Rules and Social Norms in Japan's Secret World of Sumo. Journal of Legal Studies, 26, 165-201

Wolfers, J. (2006). Corruption in NCAA Basketball. American Economic Review, 96, 279283 